\title{
Characterization of Slag Reprocessing Tailings-Based Geopolymers in Marine Environment
}

\author{
Jie Wu, Jing Li, Feng Rao * and Wanzhong Yin * \\ School of Zijin Mining, Fuzhou University, Fuzhou 350108, China; abbyduola@163.com (J.W.); \\ lijing610082858@163.com (J.L.) \\ * Correspondence: fengrao@fzu.edu.cn (F.R.); yinwanzhong@163.com (W.Y.)
}

Received: 30 July 2020; Accepted: 10 September 2020; Published: 22 September 2020

\begin{abstract}
In this study, copper slag reprocessing tailings (CSRT) were synthesized into geopolymers with $40 \%, 50 \%$ and $60 \%$ metakaolin. The evolution of compressive strength and microstructures of CSRT-based geopolymers in a marine environment was investigated. Except for compressive strength measurement, the characterizations of X-ray diffraction (XRD), Fourier-transform infrared spectroscopy (FTIR), nuclear magnetic resonance (NMR) and scanning electron microscopy (SEM) were included. It was found that marine conditions changed the $\mathrm{Si} / \mathrm{Al}$ ratio in the sodium-aluminosilicate-hydrate (N-A-S-H) gel backbone, promoted the geopolymerization process, led to more $Q^{4}(3 A l), Q^{4}(2 A l)$ and $Q^{4}(1 A l)$ gel formation and a higher compressive strength of the geopolymers. This provided a basis for the preparation of CSRT-based geopolymers into marine concrete.
\end{abstract}

Keywords: copper slag reprocessing tailings; geopolymer; microstructure; NMR

\section{Introduction}

Massive quantities of copper mine tailings are discharged from the beneficiation of the copper mine, which causes some environmental problems such as contamination of surrounding air, water bodies and soils, when disposed of in tailings storage facilities without rehabilitation [1,2]. Therefore, it is necessary to develop methods to reprocess the mine tailings to relieve their adverse impacts, whilst, at the same time, recycle resources and increase economic benefit. In the past decade, researchers used alkaline activation or the geopolymerization process for the consolidation of tailings $[3,4]$. Accordingly, the tailings are employed as raw materials in the alkaline activation process, in which the aluminosilicates in tailings are attacked by alkalis to decompose monomers and then to regroup and harden. For example, Ahmari et al. used sodium hydroxide as an alkaline activator to prepare copper mine tailings-based geopolymers, which were suitable for application of road base material at a room temperature [5]. Cristelo et al. applied fly ash as additive, and sodium hydroxide and sodium silicate as alkaline activators to prepare high-sulfur copper mine tailings-based geopolymer, which had a maximum compressive strength of $23.5 \mathrm{MPa}$ [6]. Generally, mine tailings contain a substantial amount of crystal minerals and exhibit inert in geopolymeric reaction, so that the calcination of the tailings or addition of calcined materials (e.g., metakaolin and slag) is usually necessary; the reasons are: (1) the calcined materials (e.g., metakaolin and slag) have a large amount of silicon, aluminum and calcium, which are vital elements required for geopolymerization, (2) the calcined raw materials usually have a fast dissolution and gelation rate that makes geopolymers show high early compressive strength. [7]. The calcination induces dehydroxylation of the precursor materials and enhances their amorphous phase content, so that the dissolution of silicate and aluminate monomers is favorable in the formation of sodium-aluminosilicate-hydrate (N-A-S-H) gel [8]. 
Recently, geopolymer has become an emerging marine material, because of its particular microstructure. Some researchers considered the compact tetrahedral aluminosilicate structure might protect the geopolymer concrete from attack by corrosive ions in harsh marine conditions $[9,10]$. For instance, a metakaolin-based geopolymer was synthesized with sodium hydroxide and sodium silicate mixture as alkaline activator and exposed to seawater for 28 days, whose compressive strength exceeded $20 \mathrm{MPa}$ [11]. Therefore, in this work, copper slag reprocessing tailings (CSRT)-based geopolymers were prepared and characterized in marine environment, in order to provide guidance for the preparation of tailings into marine concrete. Copper tailings have a significant amount of silicon, aluminum and calcium, which are crucial elements needed for geopolymerization. It was hypothesized that (1) the slag flotation tailings would have higher reactivity than other copper mine tailings in the geopolymerization process; (2) the formed geopolymers would have higher resistance against corrosion in the marine environment than ordinary Portland cement (OPC) concrete. After preparation, the CSRT-based geopolymers cured in air, artificial seawater and heat-cool cycles in seawater were analyzed.

\section{Experimental}

\subsection{Materials}

Copper mine tailings were obtained from the copper slag reprocessing tailings of Zijin Shan, Longyan, Fujian province, China. Kaolinite was purchased in Wuhan, Hubei province, China, which was used to prepare metakaolin through calcination at $800{ }^{\circ} \mathrm{C}$ for $6 \mathrm{~h}$. Figure 1 gives the size distribution of the CSRT and metakaolin measured by a laser diffraction analyzer (LS-CWM, Omec, Zhuhai, China), in which the $d_{50}$ and $d_{85}$ are 16.81 and $36.71 \mu \mathrm{m}$ for CSRT, and 2.38 and $3.52 \mu \mathrm{m}$ for metakaolin, respectively. Table 1 shows the chemical composition of the CSRT and metakaolin analyzed by an X-ray fluorescence instrument (XRF, Axios advanced, PANalytical B.V., Almelo, The Netherlands). The CSRT mainly contained $\mathrm{SiO}_{2}(28.19 \%)$ and $\mathrm{Fe}_{2} \mathrm{O}_{3}(57.83 \%)$, while $\mathrm{SiO}_{2}(52.67 \%)$ and $\mathrm{Al}_{2} \mathrm{O}_{3}(41.37 \%)$ were the main components of the metakaolin. Figure 2 shows the main components of the CSRT and metakaolin characterized by X-ray diffraction (XRD, D8, Brucker, Karlsruhe, Germany). The CSRT mainly contained magnetite and fayalite, while metakaolin showed an amorphous peak at $2 \theta$ of $15-30^{\circ}$ and crystal phase in quartz. Sodium silicate (ACS reagent grade), employed as an alkali activator, was bought from Aladdin Chemical Reagent (Shanghai, China) in the geopolymerization process. Deionized water was used throughout the whole process.

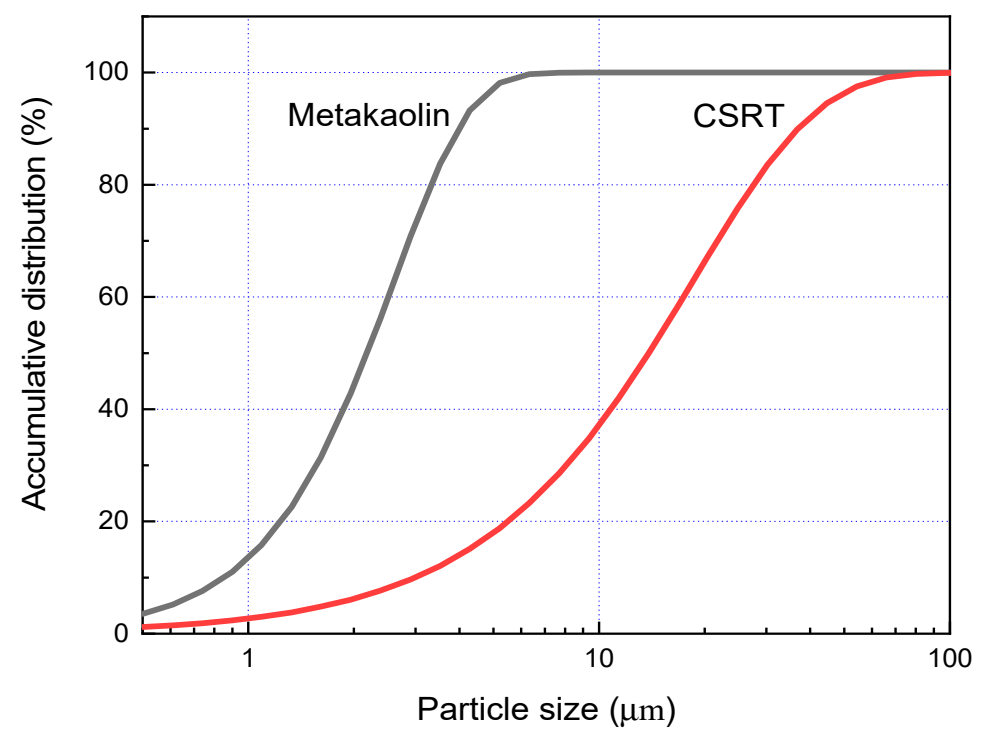

Figure 1. Size distribution of the tailings and metakaolin samples. 
Table 1. Chemical composition of the, copper slag reprocessing tailings (CSRT) and metakaolin.

\begin{tabular}{ccccccccc}
\hline Components (\%) & $\mathrm{SiO}_{2}$ & $\mathrm{Al}_{\mathbf{2}} \mathrm{O}_{\mathbf{3}}$ & $\mathrm{Fe}_{2} \mathbf{O}_{3}$ & $\mathbf{M g O}$ & $\mathrm{CaO}$ & $\mathrm{TiO}_{2}$ & $\mathrm{Na}_{2} \mathrm{O}_{2}$ & $\mathbf{K}_{\mathbf{2}} \mathbf{O}$ \\
\hline CSRT & 28.19 & 4.24 & 57.83 & 1.101 & 1.906 & 0.303 & 0.525 & 0.81 \\
\hline Metakaolin & 52.67 & 41.37 & 1.299 & 0.32 & 0.02 & 0.163 & 0.092 & 2.08 \\
\hline
\end{tabular}

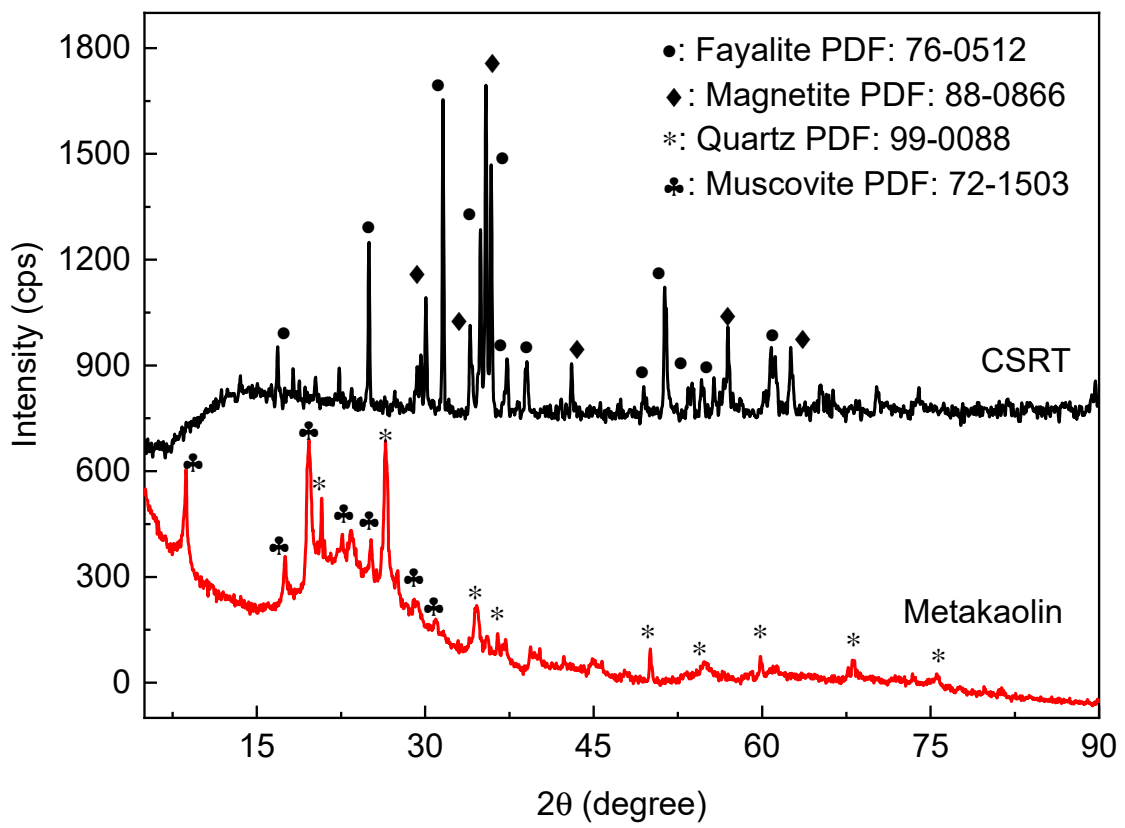

Figure 2. XRD patterns of the CSRT and metakaolin.

\subsection{Methods}

For the synthesis of the CSRT-based geopolymer, the activating solution was prepared by sodium silicate solution $(6.17 \mathrm{M})$, and then mixed with the raw materials of CSRT and metakaolin for $10 \mathrm{~min}$, which were of $40 \%, 50 \%$ and $60 \%$ metakaolin and a total solid of $192 \mathrm{~g}$. Subsequently, the mixture was put into cubic steel molds $(30 \mathrm{~mm} \times 30 \mathrm{~mm} \times 30 \mathrm{~mm})$, which were vibrated to liberate air bubbles on a vibration table for $5 \mathrm{~min}$. Next, the molds were sealed with a plastic sealing bag and cured at $60{ }^{\circ} \mathrm{C}$ for $12 \mathrm{~h}$ and left at room temperature for 7 days to complete the hydrate process of geopolymers to get the initial CSRT-based geopolymer. After that, the initial geopolymers were exposed or cured under three types of environment for 30 days: (1) in air; (2) in artificial seawater; (3) in a heat-cool seawater cycle. Geopolymers were exposed to artificial seawater at room temperature for $12 \mathrm{~h}$ and $12 \mathrm{~h}$ under the cycle in a freezer $\left(-18{ }^{\circ} \mathrm{C}\right)$. Artificial seawater with 10-fold concentration was made with $292.5 \mathrm{~g} / \mathrm{L}$ $\mathrm{NaCl}, 7.45 \mathrm{~g} / \mathrm{L} \mathrm{KCl}, 36 \mathrm{~g} / \mathrm{L} \mathrm{MgSO}_{4}$. The artificial seawater was renewed every seven days throughout the whole curing process [12].

The compressive strength of the CSRT-based geopolymers was analyzed by a YAW-300 compression and flexure machine from Jinan Tianchen manufacture (Jinan, China). Three geopolymer samples were tested and the mean value was given in each measurement. The morphology and microstructure of the geopolymers were characterized using a scanning electron microscope (SEM, Quanta 250, FEI, Hillsboro, OR, USA) and XRD diffractometer. The geopolymer was ground to less than $75 \mu \mathrm{m}$ to prepare specimens for XRD measurements, in which $\mathrm{Cu}-\mathrm{K} \alpha 1$ radiation and a scanning rate of $0.1^{\circ} / \mathrm{s}$ from $5^{\circ}$ to $90^{\circ}$ of $2 \theta$ were used. The geopolymers were also analyzed for the microstructure by employing a Fourier-transform infrared spectroscopy (FTIR, Nicolet, Thermo Fisher Scientific, Waltham, MA, USA), of which transmittance spectra were obtained over a wavenumber of $400-4000 \mathrm{~cm}^{-1}$; the resolution was $2 \mathrm{~cm}^{-1}$. The interactions of silicate in the geopolymers were measured by a ${ }^{29} \mathrm{Si}$ nuclear magnetic resonance (NMR, AVANCE III, Bruker, Zurich, Switzerland) instrument. Solid-state ${ }^{29}$ Si NMR spectra 
were collected at $99.35 \mathrm{MHz}$ with a pulse width of $4 \mu$ s (i.e., 90 degrees for quantitative analysis) and a relaxation delay of $3 \mathrm{~s}$. The spectra were referenced to tetramethylsilane (TMS).

\section{Results and Discussion}

Figure 3 shows the compressive strength of CSRT-based geopolymers prepared with different proportions of metakaolin and different exposures. The initial geopolymers, cured for 7 days, had a compressive strength of $2.3 \mathrm{MPa}, 7.8 \mathrm{MPa}$ and $15.3 \mathrm{MPa}$ when the proportion of metakaolin was $40 \%$, $50 \%$ and $60 \%$, respectively. The low value in compressive strength suggested that the CSRT had low activity in the geopolymeric reaction. Moreover, metakaolin was obviously advantageous to increase the compressive strength of the geopolymer. Compared to the initial geopolymers, the compressive strength of the geopolymers that were exposed to air for 30 days had no obvious improvement or lessening of strength. While for the geopolymers exposed to seawater for 30 days, the compressive strength increased significantly to $10.7 \mathrm{MPa}, 15.7 \mathrm{MPa}$ and $32.6 \mathrm{MPa}$ with $40 \%, 50 \%$ and $60 \%$ of metakaolin addition, respectively. For exposure to heat-cool cycles of seawater, the increase in compressive strength of geopolymers was less than those in seawater, which were 3.4 MPa, 10.2 $\mathrm{MPa}$ and $23 \mathrm{MPa}$ with $40 \%, 50 \%$ and $60 \%$ of metakaolin addition, respectively. These results show that the compressive strength of the geopolymers was improved when exposed to seawater, which is in agreement with previous studies. Sotya et al. reported that the compressive strength of geopolymers was not affected by seawater immersion [11]. Jin et al. found that cations in seawater (e.g., $\mathrm{Mg}^{2+}$ and $\mathrm{K}^{+}$) could diffuse into the aluminosilicate network structure of geopolymers to balance the negative charge, making the gel structure stable [13].

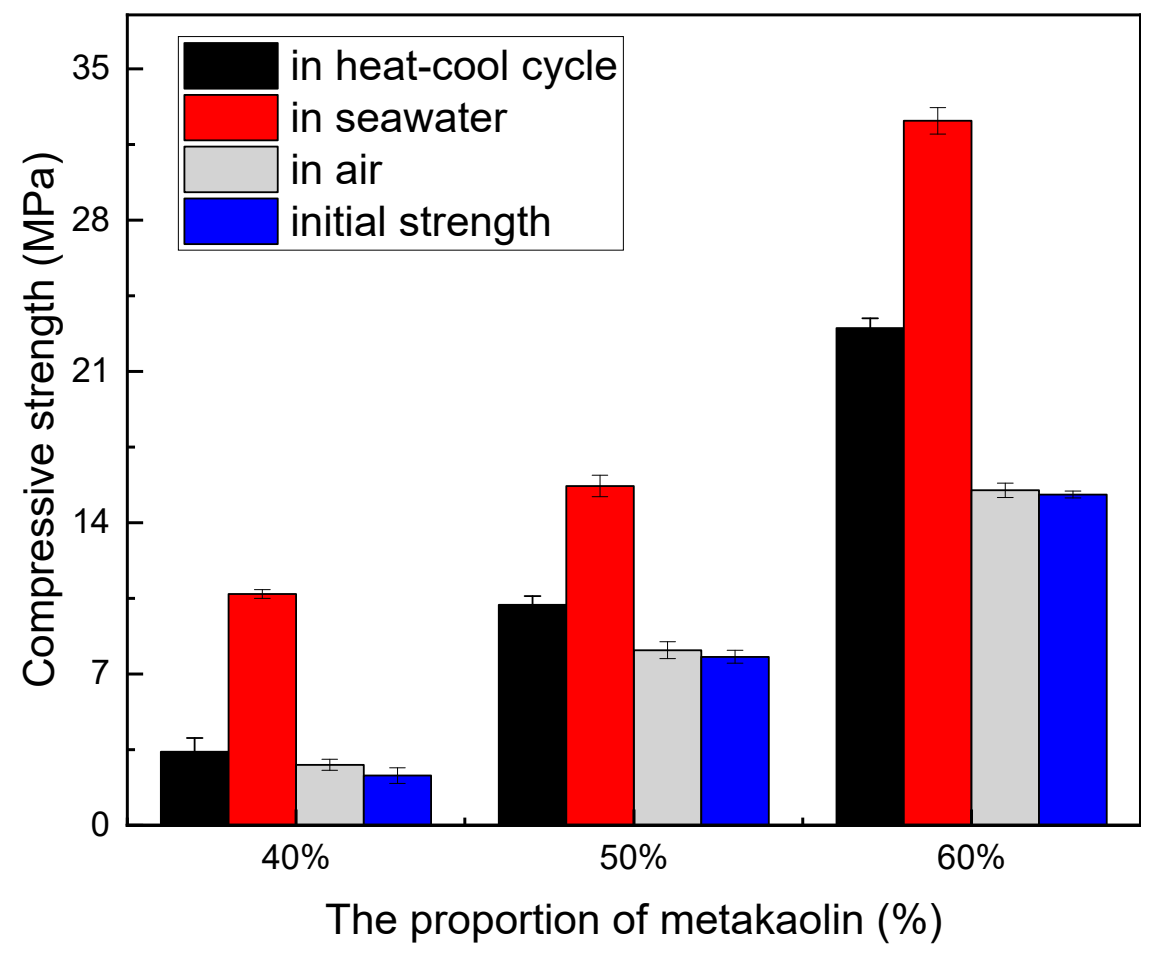

Figure 3. Compressive strength of the geopolymers prepared with different proportions of metakaolin and different exposures.

Figure 4 gives the XRD spectra of the geopolymers prepared with $60 \%$ metakaolin and which underwent different exposures for 30 days. Compared to the XRD patterns of raw materials (Figure 2), the crystal phases of quartz, magnetite, fayalite and muscovite remained after the geopolymeric reaction. While for exposure in seawater, the solution penetrated pores and precipitated halite $(\mathrm{NaCl})$ 
was observed. The range of broad peak at $2 \theta$ of $15-30^{\circ}$ in metakaolin transformed into $2 \theta$ of $22-35^{\circ}$ in the geopolymers with different exposures, which indicates the formation of N-A-S-H gel [14,15].

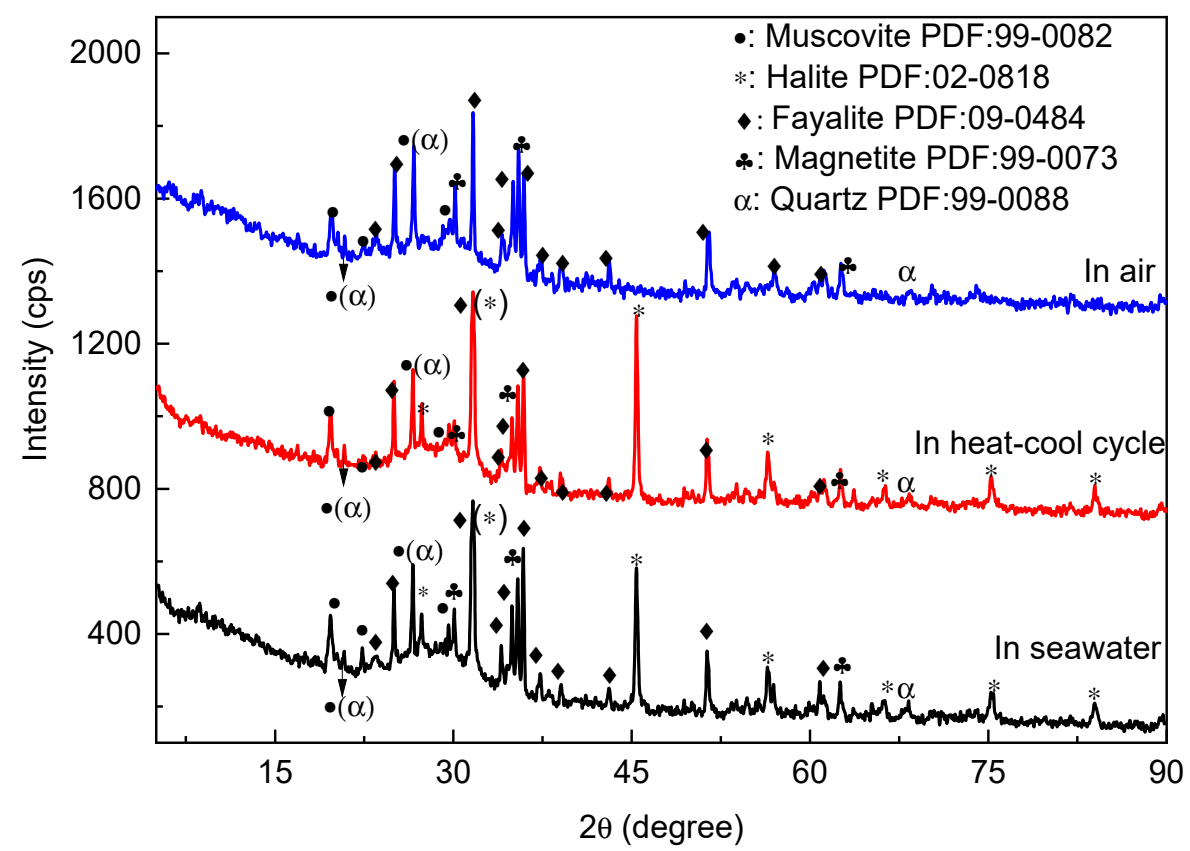

Figure 4. XRD spectra of the geopolymers prepared with $60 \%$ metakaolin.

Figure 5 shows the FTIR spectra of geopolymers prepared with $60 \%$ metakaolin and different exposures. The absorption peaks at $3440 \mathrm{~cm}^{-1}$ and $1644 \mathrm{~cm}^{-1}$ are due to stretching vibrations of $\mathrm{OH}^{-}$, and $\mathrm{H}-\mathrm{OH}$ bonds of free water, respectively, corresponding to adsorbed $\mathrm{H}_{2} \mathrm{O}$ in geopolymers [16]. The absorption peak around $1453 \mathrm{~cm}^{-1}$ is assigned to asymmetric stretching of $\mathrm{O}-\mathrm{C}-\mathrm{O}$ bonds in $\mathrm{CO}_{3}{ }^{2-}$ groups, due to carbonation in the curing and exposing process of geopolymers [17]. The peak at $699 \mathrm{~cm}^{-1}$ is the Si-O bonds in quartz, suggesting the quartz particles are insoluble in the geopolymeric reaction [18]. The absorption peaks at $560 \mathrm{~cm}^{-1}$ and $460 \mathrm{~cm}^{-1}$ represent the zeolite framework in the structure of the geopolymer $[19,20]$, which indicates zeolite frameworks are formed during the process. The band at about $1000 \mathrm{~cm}^{-1}$ is the Si-O-T bonds ( $\mathrm{T}$ represents the tetrahedral $\mathrm{Al}$ or $\mathrm{Si}$ ) in the geopolymer gel [21]. It is sensitive to the Si/Al ratio in the geopolymer backbone, which could shift toward the lower wavenumber at a low Si/Al ratio [22]. The wavenumber transformation indicates the exposure in the heat-cool cycle and seawater, which changed the evolution of the N-A-S-H gel. In addition, the higher intensity for the geopolymers exposed to seawater than in the heat-cool cycle and in air, suggests the formation of higher proportions of N-A-S-H gel.

NMR spectroscopy is an excellent analytical method for characterizing the short-range ordering and molecular structure of silicates $[23,24]$. It employs Gaussian peak deconvolution to overcome the lack of spectra resolution and separate and quantify $Q^{\mathrm{n}}(\mathrm{mAl})$ species $(0 \leq m \leq n \leq 4, m, n=$ integer $)$. The resonances at -74 and $-79 \mathrm{ppm}$ are assigned to $\left(Q^{0}\right)$ and $\left(Q^{1}\right)$, respectively, due to the presence of silicate monomer and dimer [25]. The resonance at -104 ppm represents $Q^{3}(R)$ when $\mathrm{H}$ in $\mathrm{OH}$ is substituted by alkali metal ion $\left(\mathrm{Na}^{+}\right.$or $\left.\mathrm{K}^{+}\right)$in $Q^{3}$ [2], and the resonance at -114 ppm corresponds to the cristobalite in the geopolymers [26]. In geopolymer N-A-S-H gel, the $Q^{4}(4 A l), Q^{4}(3 A l), Q^{4}(2 A l)$, $Q^{4}(1 A l), Q^{4}(0 A l)$ resonate at around $-84,-89,-93,-99$ and -108 ppm, respectively [19]. 


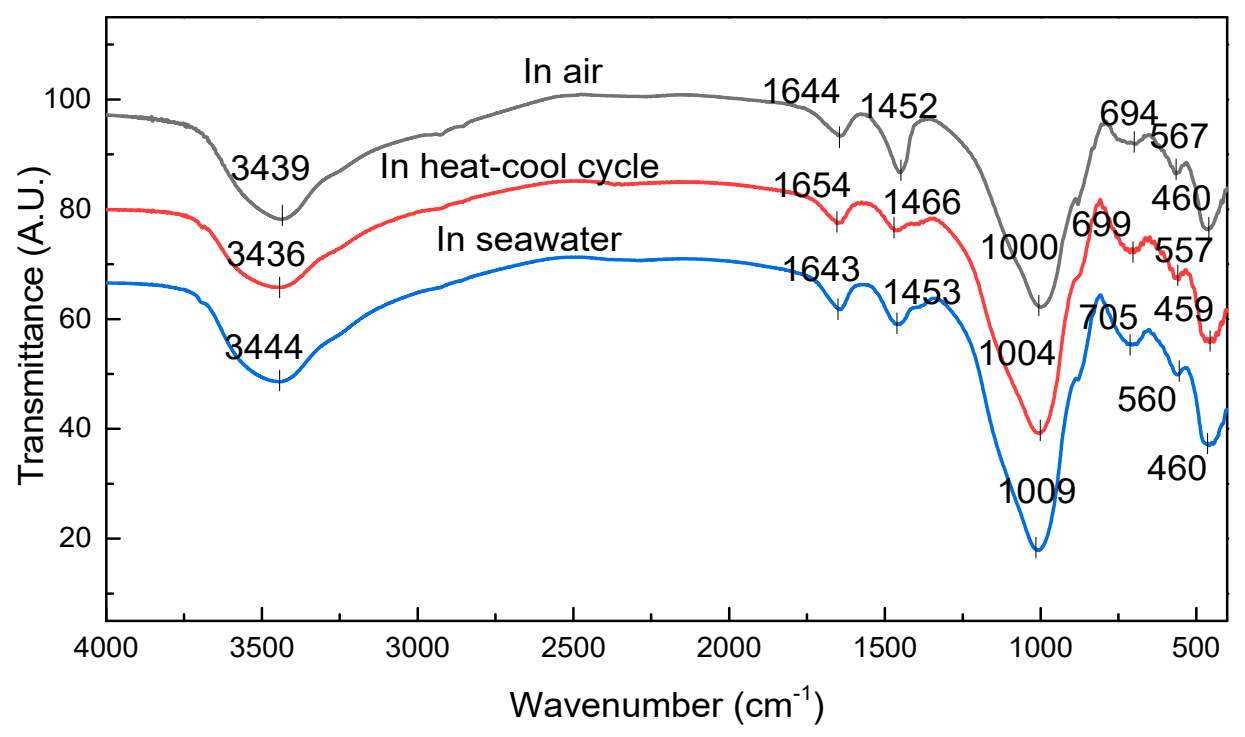

Figure 5. FTIR spectra of the geopolymers prepared with $60 \%$ metakaolin and different exposures.

Figure 6 gives the ${ }^{29} \mathrm{Si}$ NMR spectra and deconvolution of the raw metakaolin and CSRT-based geopolymers prepared with $60 \%$ metakaolin and exposed differently for 30 days. Metakaolin predominantly peaked at around $-105 \mathrm{ppm}$. After geopolymerization, the ${ }^{29} \mathrm{Si}$ NMR lines shifted to less shielded values due to the geopolymeric reaction taking place to form N-A-S-H gel. For the geopolymers exposed to air, the heat-cool cycle and seawater, the Si sites in silicate monomers $\left(Q^{0}\right)$ are $1.39 \%, 1.26 \%$ and $1.23 \%$, those in silicate dimer $\left(Q^{1}\right)$ are $8.63 \%, 6.65 \%$ and $6.10 \%$, and in $Q^{3}(R)$ are $7.69 \%, 1.32 \%$ and $3.52 \%$, but those in N-A-S-H gel $\left(Q^{4}(m A l), 0 \leq m \leq 4\right)$ are $79.21 \%, 90.77 \%$, and $87.78 \%$, respectively. The $\mathrm{Si}$ sites in $Q^{0}$ and $Q^{1}$ slightly decrease and those in N-A-S-H gel increase when the geopolymers are exposed to seawater, indicating that the $Q^{0}$ and $Q^{1}$ transformed into N-A-S-H gel. It has been reported that the compressive strength relies on the amount of $Q^{4}(3 A l), Q^{4}(2 A l)$ and $Q^{4}(1 A l)$ [27]. The percentages of $Q^{4}(3 A l), Q^{4}(2 A l)$ and $Q^{4}(1 A l)$ are $51.08 \%, 63.78 \%$ and $64.78 \%$ for the exposures in air, heat-cool cycle and seawater, respectively, which explained the variation in compressive strength of geopolymers. These results suggest that exposure in seawater promotes the geopolymerization process.

Figure 7 shows the SEM morphology of the geopolymers that underwent different exposures for 30 days. The geopolymers exposed to both the heat-cool cycle and seawater showed homogenous and compact structures, indicating geopolymers with $60 \%$ metakaolin can be consolidated well. However, cracks were exhibited in geopolymers exposed to air. This result further confirmed that more N-A-S-H gel was formed in the geopolymers that were exposed to both the heat-cool cycle and seawater, thereby bridging the cracks, and thus increasing their compressive strength.

In this study, the geopolymers exposed to seawater showed a high formation of N-A-S-H gel, thereby exhibited a higher compressive strength than the geopolymers exposed to air. When geopolymers were exposed to the marine environment, alkaline ions (e.g., $\mathrm{Mg}^{2+}, \mathrm{Na}^{+}$) in seawater functioned as balancing cations to the negative charge of the tetra-coordinated aluminum, thereby promoting the geopolymerization process [28]. Therefore, for the geopolymers exposed to seawater, more Si-O-T gel was formed (Figure 5) and the $Q^{0}$ and $Q^{1}$ species were transformed into N-A-S-H gel (Figure 6). 

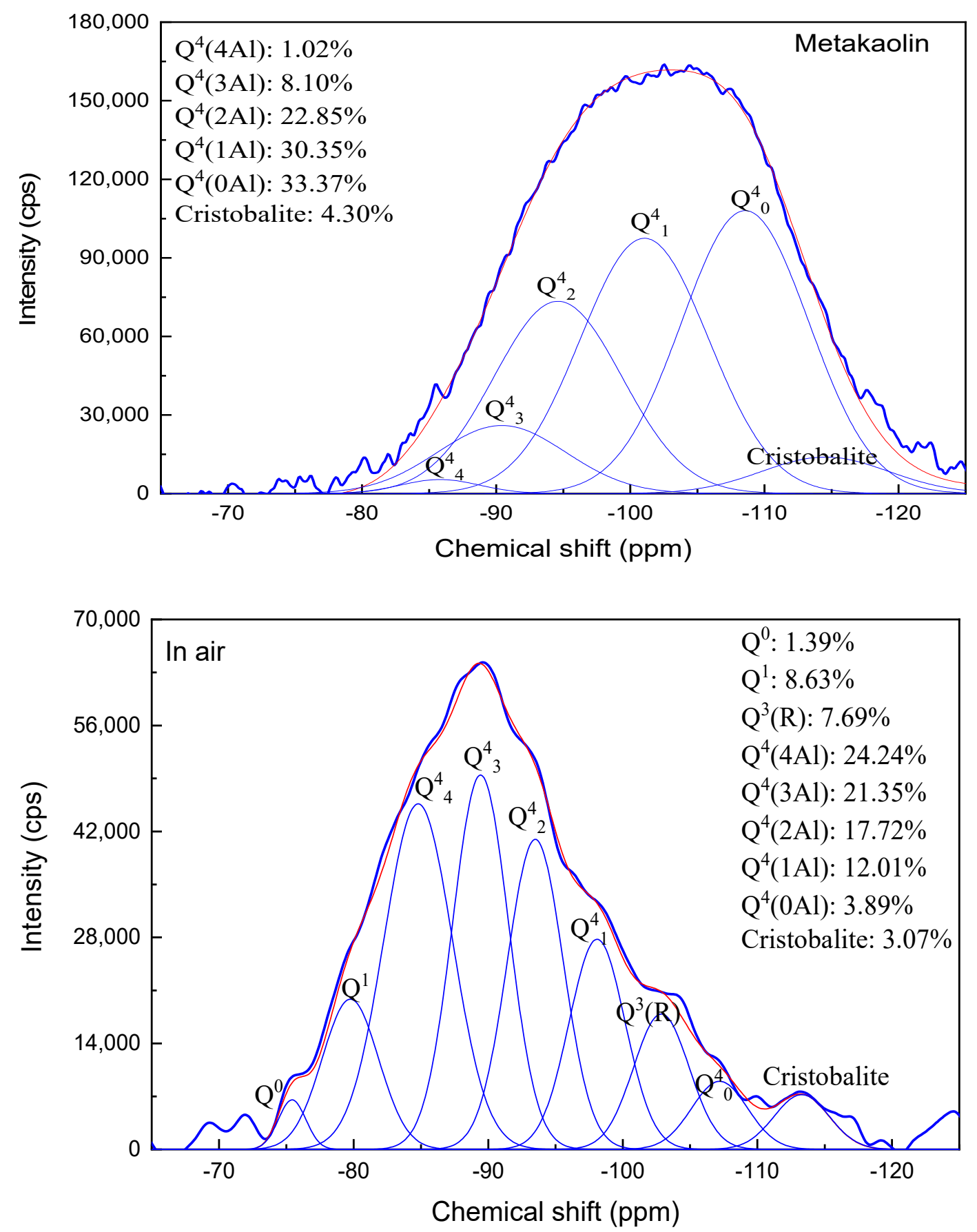

Figure 6. Cont. 

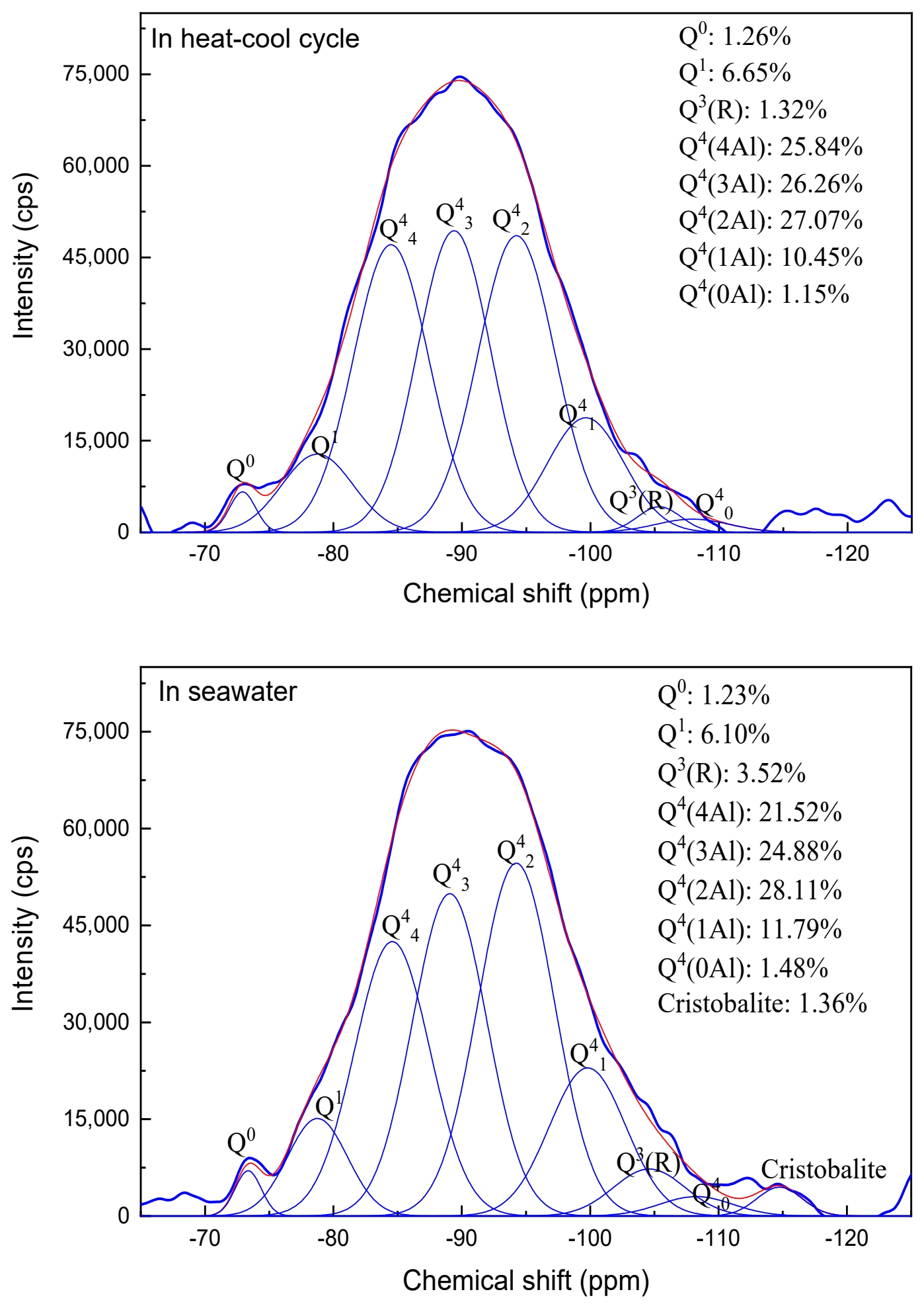

Figure 6. ${ }^{29} \mathrm{Si}$ NMR spectra and deconvolution of the geopolymers prepared with $60 \%$ metakaolin. 

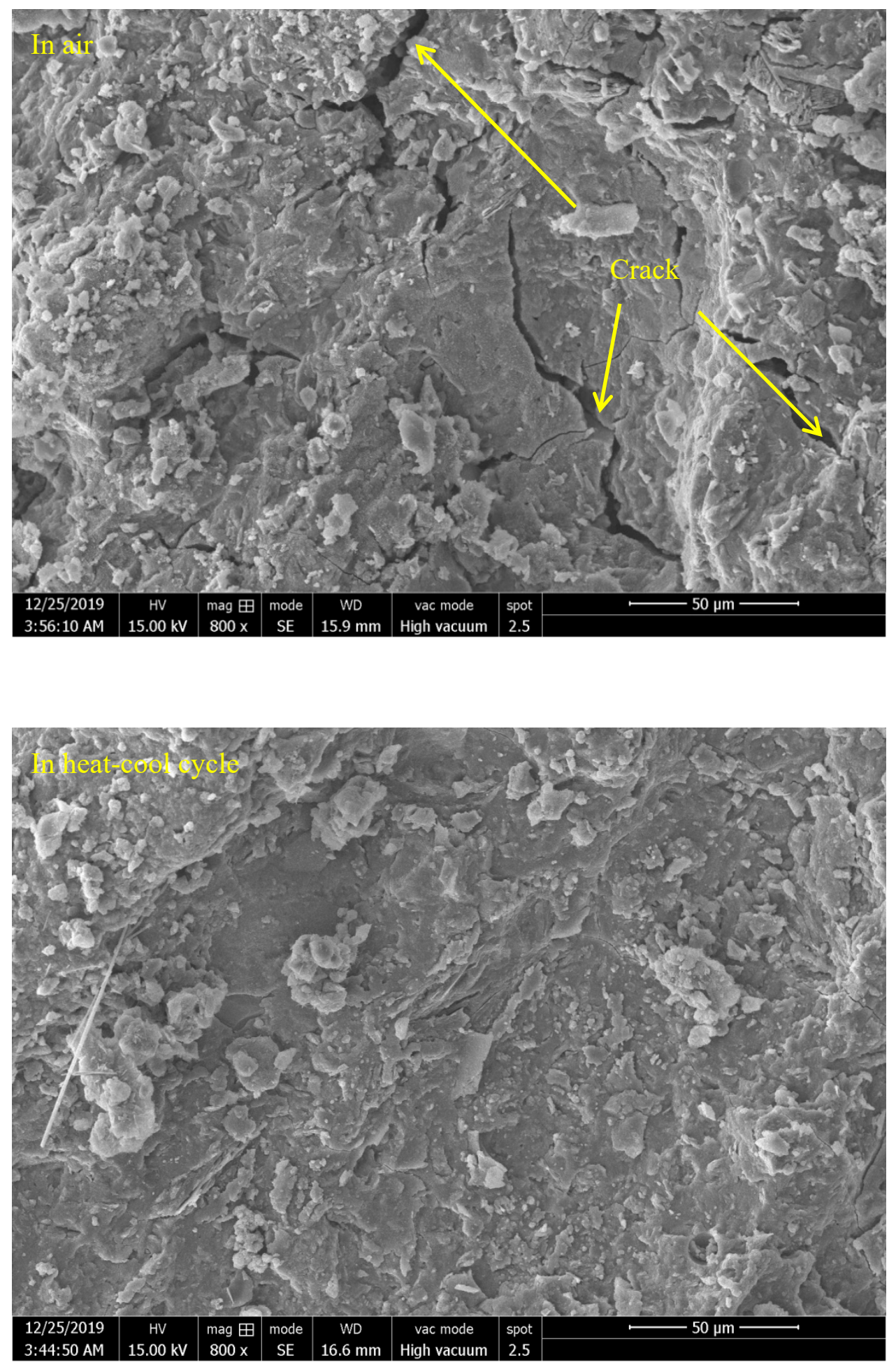

Figure 7. Cont. 


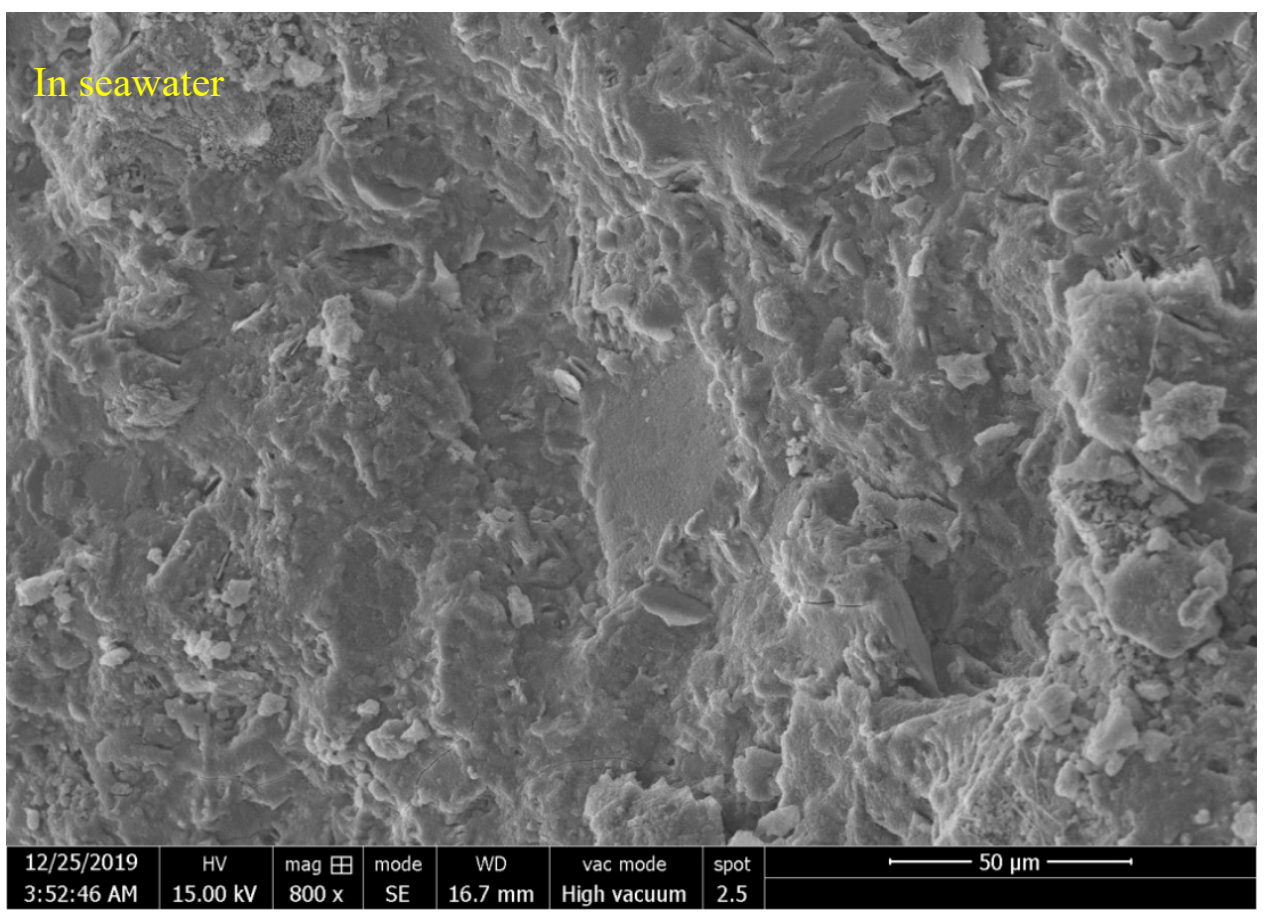

Figure 7. SEM images of the geopolymers prepared with $60 \%$ metakaolin.

\section{Conclusions}

Mine tailings after the flotation of copper slag are synthesized into geopolymers with the addition of metakaolin (40-60\%), which enhances their compressive strength. For the geopolymers exposed to seawater, the $\mathrm{Si} / \mathrm{Al}$ changed in the $\mathrm{N}-\mathrm{A}-\mathrm{S}-\mathrm{H}$ gel backbone, more $Q^{4}(3 A l), Q^{4}(2 A l)$ and $Q^{4}(1 A l)$ gel and fewer cracks formed, resulting in a higher compressive strength being observed for these geopolymers than for those exposed to the heat-cool cycle of seawater and in air. This is attributed to the fact that alkaline ions in seawater balance the negative charge of the aluminum tetrahedrons in geopolymers, which promote the formation of N-A-S-H gel. As understanding the evolution of geopolymer in marine environments is important, this study is of significance and would benefit the development of marine concrete incorporating tailings. The optimization of compressive strength and long-term durability of the CRST-based geopolymer and tailoring of CRST-based geopolymer marine concrete should be studied in the future.

Author Contributions: J.W.: figures, study design, data collection, data analysis, and writing. J.L.: literature search, figures. F.R.: study design, data analysis, data interpretation, and writing. W.Y.: study design, data analysis, and data interpretation. All authors have read and agreed to the published version of the manuscript.

Funding: This study was financially supported by the National Natural Science Foundation of China under the project No. 51974093 and the Fuzhou University Qishan Scholar Talent Foundation under the Grant No. GXRC-18042, for which the authors are grateful.

Conflicts of Interest: We declare that we do not have any commercial or associative interest that represents a conflict of interest in connection with the work submitted.

\section{References}

1. Park, I.; Tabelin, C.B.; Jeon, S.; Li, X.; Seno, K.; Ito, M.; Hiroyoshi, N. A review of recent strategies for acid mine drainage prevention and mine tailings recycling. Chemosphere 2018, 219, 588-606. [CrossRef] [PubMed]

2. Tian, X.; Xu, W.; Song, S.; Rao, F.; Xia, L. Effects of curing temperature on the compressive strength and microstructure of copper tailing-based geopolymers. Chemosphere 2020, 253, 126754. [CrossRef] [PubMed]

3. Yang, F. Geopolymerization of Copper Mine Tailings; The University of Arizona: Tucson, AZ, USA, 2012. 
4. Ahmari, S.; Zhang, L.; Zhang, J. Effects of activator type/concentration and curing temperature on alkali-activated binder based on copper mine tailings. J. Mater. Sci. 2012, 47, 5933-5945. [CrossRef]

5. Ahmari, S.; Chen, R.; Zhang, L. Utilization of mine tailings as road base material. In American Society of Civil Engineers GeoCongress; ASCE: Oakland, CA, USA, 2012; pp. 3654-3661.

6. Cristelo, N.; Coelho, J.; Oliveira, M.; Consoli, N.C.; Palomo, Á.; Fernández-Jiménez, A. Recycling and application of mine tailings in alkali-activated cements and mortars-strength development and environmental assessment. Appl. Sci. 2020, 10, 2084. [CrossRef]

7. Marescotti, P.; Carbone, C.; Capitani, L.D.; Grieco, G.; Lucchetti, G.; Servida, D. Mineralogical and geochemical characterisation of open-air tailing and waste-rock dumps from the Libiola Fe-Cu sulphide mine (Eastern Liguria, Italy). Environ. Geol. 2008, 53, 1613-1626. [CrossRef]

8. Moukannaa, S.; Nazari, A.; Bagheri, A.; Loutou, M.; Sanjayan, J.G.; Hakkou, R. Alkaline fused phosphate mine tailings for geopolymer mortar synthesis: Thermal stability, mechanical and microstructural properties. J. Non-Cryst. Solids. 2019, 511, 76-85. [CrossRef]

9. Kwan, W.H.; Cheah, C.B.; Ramli, M.; Chang, K.Y. Alkali-resistant glass fiber reinforced high strength concrete in simulated aggressive environment. Mater. Constr. 2018, 63, 62-71. [CrossRef]

10. Albitar, M.; Mohamed Ali, M.; Visintin, P.; Drechsler, M. Durability evaluation of geopolymer and conventional concretes. Constr. Build. Mater. 2017, 136, 374-385. [CrossRef]

11. Sotya, A.; Marta, N.D.; Wibowo, A.H.; Niken, S. Durability of geopolymer concrete upon seawater exposure. Adv. Sci. Technol. 2010, 69, 92-96.

12. Li, X.; Rao, F.; Song, S.; Ma, Q. Deterioration in the microstructure of metakaolin-based geopolymers in marine environment. J. Mater. Res. Technol. 2019, 8, 2747-2752. [CrossRef]

13. Jin, M.; Chen, Y.; Dong, H.; Chen, L.; Jin, Z. Seawater erosion resistance of geopolymer solidification MSWI fly ash. Acta Mieralogiga Sin. 2014, 34, 159-165. (In Chinese)

14. Bernal, S.A.; Provis, J.L.; Walkley, B.; Nicolas, R.S.; Gehman, J.D.; Brice, D.G.; Kilcullen, A.R.; Duxson, P.; Deventer, J.S.J. Van Gel nanostructure in alkali-activated binders based on slag and fly ash, and effects of accelerated carbonation. Cem. Concr. Res. 2013, 53, 127-144. [CrossRef]

15. Lee, N.K.; Koh, K.T.; An, G.H.; Ryu., G.S. Influence of binder composition on the gel structure in alkali activated fly ash/slag pastes exposed to elevated temperatures. Ceram. Int. 2017, 43, 2471-2480. [CrossRef]

16. Bernal, S.A.; Provis, J.L.; Rose, V.; de Gutierrez, R.M. Evolution of binder structure in sodium silicate-activated slag-metakaolin blends. Cem. Concr. Compos. 2011, 33, 46-54. [CrossRef]

17. Yang, T.; Xiao, Y.A.O.; Zuhua, Z.; Huajun, Z.H.U. Effects of $\mathrm{NaOH}$ solution concentration and reaction time on metakaolin geopolymerization. J. Nanjing Univ. Technol. 2013, 35, 21-25.

18. Wan, Q.; Rao, F.; Song, S.; Cholico-González, D.F.; Ortiz, N.L. Combination formation in the reinforcement of metakaolin geopolymers with quartz sand. Cem. Concr. Compos. 2017, 80, 115-122. [CrossRef]

19. Engelhardt, G.; Michel, D. High-Resolution Solid-State NMR of Silicates and Zeolites; Wily: New York, NY, USA, 1987.

20. Mostafa, N.Y.; El-Hemaly, S.A.S.; Al-Wakeel, E.I.; El-Korashy, S.A.; Brown, P.W. Characterization and evaluation of the pozzolanic activity of Egyptian industrial by-products: I: Silica fume and dealuminated kaolin. Cem. Concr. Res. 2001, 31, 467-474. [CrossRef]

21. Palomo, A.; Blanco-Varela, M.T.; Granizo, M.L.; Puertas, F.; Grutzeck, M.W. Chemical Stability of Cementitious Materials Based on Metakaolin. Cem. Concr. Res. 1999, 29, 997-1004. [CrossRef]

22. Zheng, L.; Wang, W.; Shi, Y. The effects of alkaline dosage and Si/Al ratio on the immobilization of heavy metals in municipal solid waste incineration fly ash-based geopolymer. Chemosphere 2010, 79, 665-671. [CrossRef]

23. Tian, X.; Rao, F.; Morales-Estrella, R.; Song, S. Effects of Aluminum Dosage on Gel Formation and Heavy Metal Immobilization in Alkali-Activated Municipal Solid Waste Incineration Fly Ash. Energy Fuels 2020, 34, 4727-4733. [CrossRef]

24. Klinowski, J. Nuclear magnetic resonance studies of zeolites. Prog. Nucl. Magn. Reson. Spectrosc. 1984, 16, 237-309. [CrossRef]

25. Singh, P.S.; Bastow, T.; Trigg, M. Structural studies of geopolymers by ${ }^{29}$ Si and ${ }^{27}$ Al MAS-NMR. J. Mater. Sci. 2005, 40, 3951-3961. [CrossRef]

26. Fernández-Jiménez, A.; Palomo, A.; Sobrados, I.; Sanz, J. The role played by the reactive alumina content in the alkaline activation of fly ashes. Microporous Mesoporous Mater. 2006, 91, 111-119. [CrossRef] 
27. Wan, Q.; Rao, F.; Song, S.; García, R.E.; Estrella, R.M.; Patiño, C.L.; Zhang, Y. Geopolymerization reaction, microstructure and simulation of metakaolin-based geopolymers at extended $\mathrm{Si} / \mathrm{Al}$ ratios. Cem. Concr. Compos. 2017, 79, 45-52. [CrossRef]

28. Davidovits, J. Geopolymer chemistry and properties. In Proceedings of the 1st European Conference on Soft Mineralogy, Compiègne, France, 1-3 June 1988; Volume 1, pp. 25-48.

(C) 2020 by the authors. Licensee MDPI, Basel, Switzerland. This article is an open access article distributed under the terms and conditions of the Creative Commons Attribution (CC BY) license (http://creativecommons.org/licenses/by/4.0/). 